\title{
(1E,4E)-2-Methyl-1,5-bis(4-nitrophenyl)penta-1,4-dien-3-one on Trypanosoma cruzi and Its Combinational Effect with Benznidazole, Ketoconazole, or Fluconazole
}

\author{
Francieli Peron, ${ }^{1}$ Danielle Lazarin-Bidóia, ${ }^{2}$ Zia Ud Din, ${ }^{3}$ Edson Rodrigues-Filho, ${ }^{3}$ \\ Tânia Ueda-Nakamura, ${ }^{2}$ Sueli de Oliveira Silva, ${ }^{2}$ and Celso Vataru Nakamuraa, ${ }^{1,2}$ \\ ${ }^{1}$ Programa de Pós-Graduação em Ciências Biológicas, Universidade Estadual de Maringá, Av. Colombo 5790, \\ 87020-900 Maringá, PR, Brazil \\ ${ }^{2}$ Programa de Pós-Graduação em Ciências Farmacêuticas, Universidade Estadual de Maringá, Av. Colombo 5790, \\ 87020-900 Maringá, PR, Brazil \\ ${ }^{3}$ LaBioMMi, Departamento de Química, Universidade Federal de São Carlos, CP 676, 13.565-905 São Carlos, SP, Brazil \\ Correspondence should be addressed to Celso Vataru Nakamura; cvnakamura@uem.br
}

Received 23 August 2016; Revised 25 November 2016; Accepted 10 January 2017; Published 23 May 2017

Academic Editor: Antonella Di Sotto

Copyright (C) 2017 Francieli Peron et al. This is an open access article distributed under the Creative Commons Attribution License, which permits unrestricted use, distribution, and reproduction in any medium, provided the original work is properly cited.

This study reports the activity induced by (1E,4E)-2-methyl-1,5-bis(4-nitrophenyl)penta-1,4-dien-3-one (A3K2A3) against Trypanosoma cruzi. This compound showed trypanocidal activity against the multiplicative epimastigote and amastigote forms of this protozoan, with $\mathrm{IC}_{50}$ values of $1.99 \pm 0.17$ and $1.20 \pm 0.16 \mu \mathrm{M}$, respectively, and $\mathrm{EC}_{50}$ value of $15.57 \pm 0.34 \mu \mathrm{M}$ against trypomastigotes. The combination of A3K2A3 with benznidazole or ketoconazole demonstrated strong synergism, increasing effectiveness against trypomastigotes or epimastigotes of T. cruzi. In addition, the drug combination of A3K2A3 with benznidazole or ketoconazole on $\mathrm{LLCMK}_{2}$ cells demonstrated an antagonist effect, which resulted in greater protection of the cells from drug damage. The combination of the compound with fluconazole was not effective. Transmission and scanning electron micrographs showed changes on parasites, mainly in the cytoplasmatic membrane, nucleus, mitochondrion, and Golgi complex, and a large increase in the number of autophagosome-like structures and lipid-storage bodies, accompanied by volume reduction and rounding of the parasite. A3K2A3 might be a promising compound against T. cruzi.

\section{Introduction}

Chagas disease was discovered and described in 1909 by the Brazilian physician Carlos Chagas. It is considered a public health problem in 19 American countries and about 7 to 8 million people are infected worldwide, especially in Latin America. Also, several cases of the disease have been detected in United States, Canada, Europe, and some countries of the Western Pacific [1-3].

The causative agent of Chagas disease, Trypanosoma cruzi, presents heteroxenic life cycle, involving a mammalian host and an invertebrate host (triatomine) and three main morphologically distinct evolutionary forms can be highlighted, epimastigote, trypomastigote, and amastigote [4].

Chagas disease presents itself in 2 phases: the acute phase and the chronic phase. The initial, acute phase lasts for 4-8 weeks after infection and is usually asymptomatic or could present as a self-limiting febrile illness. Additionally, some individuals can present headache, enlarged lymph glands, pallor, muscle pain, difficulty in breathing, swelling, and abdominal or chest pain. However in several cases there is still morbidity and mortality [5]. In the second, chronic stage, the infection may remain silent for decades or even for life. However, some patients suffer from cardiac disorders 
and digestive, neurological, or mixed complications. This infection can lead to sudden death or heart failure caused by progressive destruction of the heart muscle and of the nervous system [1].

The treatment is restricted to only two nitroheterocyclic compounds, benznidazole and nifurtimox, developed in the 70s [6]. Both drugs are far from ideal, due to the limited effectiveness against different strains of the parasite, the need for long-term therapy, its weak activity in the chronic phase, and systemic toxicity with serious side effects, including polyneuritis, lymphadenopathy, dermatitis, anorexia, allergic dermopathy, and depression of bone marrow [7]. Because of these adverse effects, many patients end up abandoning the treatment [8]. These drawbacks justify the need to identify new drugs that are more effective and less toxic for the treatment of patients with Chagas disease.

Several studies have been conducted to find new active compounds against T. cruzi. The search based on natural and synthetic compounds is promising, either alone or in combination, against the parasite [9-12]. It is proven that therapeutic associations are an important way of increasing efficacy and reduce the toxicity of drugs with different mechanisms of action in the treatment of many diseases [13]. Previous works have shown the importance of combination therapy against several microorganisms such as bacteria [14, 15], fungi $[16,17]$, and protozoa such as Leishmania $[18,19]$ and T. cruzi $[9,20,21]$.

Dibenzylideneacetone (DBA) is a class of compounds having an acyclic dienone attached to aryl groups in both $\beta$-positions. These structures are similar to chalcones and curcuminoids, which are important bioactive natural compounds found in several plant species. DBAs have shown antiplasmodial [22], antitumor [23], and anticancer activity inhibiting cell growth and inducing apoptosis [24]. Additionally, DBA potentiates TRAIL-induced apoptosis through downregulation of cell survival proteins and upregulation of death receptors via activation of reactive oxygen species (ROS) [25]. Recently, our research group reported trypanocidal activity of a DBA (1E,4E)-2-methyl-1,5-bis(4nitrophenyl)penta-1,4-dien-3-one (A3K2A3) against epimastigote and trypomastigote forms of T. cruzi [26].

Considering the trypanocidal activity of this compound, the aim of this study was to further evaluate the antiprotozoan activity and the main morphological and ultrastructural alterations induced by $\mathbf{A} \mathbf{3} \mathbf{K} \mathbf{2} \mathbf{A}$, against the three main forms of T. cruzi, and investigate the safety of these compounds, testing their toxicity in human red blood cells. We also verified the in vitro activity of A3K2A3 combined with benznidazole, ketoconazole, and fluconazole against T. cruzi and mammalian cells.

\section{Materials and Methods}

2.1. Synthesis of the Compound A3K2A3. The compound (1E,4E)-2-methyl-1,5-bis(4-nitrophenyl)penta-1,4-dien-3-one (A3K2A3) (Figure 1) is dibenzylideneacetone synthesized following the methodology described by Din et al. [26]. Stock solution of the compound was prepared aseptically in DMSO

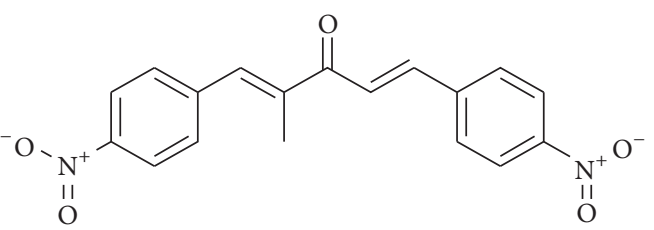

FIGURE 1: Structure of dibenzylideneacetone (1E,4E)-2-methyl-1,5bis(4-nitrophenyl)penta-1,4-dien-3-one.

and diluted in culture medium so that the DMSO concentration did not exceed $1 \%$ in the experiments.

2.2. Parasites and Mammalian Cells. Epimastigote forms of Trypanosoma cruzi (Y strain) were cultivated in Liver Infusion Tryptose (LIT) medium [27] supplemented with 10\% heat-inactivated fetal bovine serum (FBS; Gibco Invitrogen, Grand Island, NY, USA), kept at $28^{\circ} \mathrm{C}$, and maintained by weekly transfers. Trypomastigote forms were obtained from the supernatant of previously infected monolayers of LLCMK $_{2}$ cells (Macaca mulatta epithelial kidney cells; American Type Culture Collection, Rockville, MD, USA) in DMEM supplemented with $2 \mathrm{mM}$ L-glutamine, $10 \% \mathrm{FBS}$, and $50 \mathrm{mg} / \mathrm{L}$ gentamicin and buffered with sodium bicarbonate in a $5 \% \mathrm{CO}_{2}$ air mixture at $37^{\circ} \mathrm{C}$.

2.3. Antiproliferative Assay. Epimastigotes $\left(1.0 \times 10^{6}\right.$ parasites $/ \mathrm{mL}$ ) in the exponential phase of growth $(96 \mathrm{~h})$ were incubated in LIT medium plus 10\% FBS and added increasing concentrations of A3K2A3 $(1-100 \mu \mathrm{M})$ in 24-well plates. Parasites were incubated at $28^{\circ} \mathrm{C}$ and collected aseptically every $24 \mathrm{~h}$ and counted in a Neubauer hemocytometer. The $\mathrm{IC}_{50}$ (concentration that inhibited $50 \%$ of parasite growth) were determined by regression analysis of the data.

2.4. Viability Assay in Trypomastigote Forms. Trypomastigotes $\left(1.0 \times 10^{7}\right.$ parasites $\left./ \mathrm{mL}\right)$ were incubated in 96-well plates containing 20\% mouse blood or not and 20\% FBS and added increasing concentrations of A3K2A3 (1-100 $\mu \mathrm{M})$. Parasites were incubated for $24 \mathrm{~h}$ at $4^{\circ} \mathrm{C}$ or $37^{\circ} \mathrm{C}$ in $5 \% \mathrm{CO}_{2}$ atmosphere. After incubation, the viability of the parasites was examined by mobility under a light microscope (Olympus CX31) using the Pizzi-Brener method [28]. The concentration that killed $50 \%$ of the parasites $\left(\mathrm{EC}_{50}\right)$ was calculated.

2.5. Antiproliferative Assay in Intracellular Amastigotes. LLCMK $_{2}$ cells $\left(2.5 \times 10^{5}\right.$ cells $\left./ \mathrm{mL}\right)$ were added to 24 -well plates that contained round glass coverslips and incubated at $37^{\circ} \mathrm{C}$ in $5 \% \mathrm{CO}_{2}$ atmosphere until confluent growth $(24 \mathrm{~h})$. After, the cells were infected with trypomastigote forms (10:1 ratio) during $24 \mathrm{~h}$ and washed in phosphate-buffered saline (PBS). DMEM with increasing concentrations of A3K2A3 (1-100 $\mu \mathrm{M})$ was added and the cells were incubated under the same conditions for a period of $96 \mathrm{~h}$. Then, the glass coverslips were subjected to fixation with methanol and stained with May-Grunwald Giemsa for $20 \mathrm{~min}$ and permanently prepared with Entellan (Merck, Germany). The percentage of infected cells and the number of parasites per cell were 
determined by counting 200 cells under a light microscope. The survival index (\%) was obtained by multiplying the percentage of infected cells by the mean number of amastigotes per infected $\mathrm{LLCMK}_{2}$ cell. The survival index observed in the control without treatment was considered as $100 \%$ and the results for treated groups were comparatively evaluated.

2.6. Hemolytic Activity. The lytic activity of the A3K2A3 on human red blood cells evaluated using erythrocytes from a healthy human donor was obtained. For this, cells were defibrinated, washed in glycosylated saline, resuspended to $3 \%$ in glycosylated saline, and incubated with increasing concentrations of the A3K2A3 $(1-1000 \mu \mathrm{M})$ at $37^{\circ} \mathrm{C}$ for $3 \mathrm{~h}$. After, the supernatant was read in microplate (Biotek PowerWave XS) at $550 \mathrm{~nm}$. Triton X-100 (1\%) was used as a positive control.

The blood was collected by brachial vein puncture from healthy volunteer donors agreeing with Declaration of Helsinki, a set of ethical principles for medical research involving human subjects, last reviewed in 2013. All procedures were performed according to specific protocol approved by State University of Maringá (acceptance 293/ 2006 COPEP-UEM).

2.7. Drug Combination. To verify the effect of the combination of A3K2A3 associated with benznidazole, fluconazole, or ketoconazole on epimastigotes, trypomastigotes, and LLCMK $_{2}$ cells, we applied the Combination Index (CI) method proposed by Chou and Talalay [29] and revised by Zhao et al. [30]. The experimental design consists of combinations of at least four concentrations of each drug arranged in a checkerboard at a 1:2 concentration ratio. Briefly, epimastigotes $\left(1.0 \times 10^{6}\right.$ parasites $\left./ \mathrm{mL}\right)$ were resuspended in LIT medium in the presence of different concentrations of each drug in combination and counted after $96 \mathrm{~h}$ incubation at $28^{\circ} \mathrm{C}$. Trypomastigotes $\left(1.0 \times 10^{7}\right.$ parasites $\left./ \mathrm{mL}\right)$ were collected and exposed to different concentrations of drugs in combination and after $24 \mathrm{~h}$ incubation, the parasites were analyzed for viability. LLCMK $_{2}$ cells $\left(2.5 \times 10^{5}\right.$ cells $\left./ \mathrm{mL}\right)$ were plated and exposed to different concentrations of drugs in combination. After $96 \mathrm{~h}$, cell viability was quantified using the MTT method [31]. The data were calculated and mathematically expressed as the Combination Index $\left(\mathrm{CI}=\left[\mathrm{IC}_{50}\right.\right.$ drug $\mathrm{A}$ combined $/ \mathrm{IC}_{50}$ drug A alone $]+\left[\mathrm{IC}_{50}\right.$ drug B combined $/ \mathrm{IC}_{50}$ drug $\mathrm{B}$ alone]), the numerators represent the combined concentration of each drug that inhibited $50 \%$ of the growth of the cells, the denominator is the concentration of each drug alone that exhibited the same effect. The resulting CI theorem of Chou-Talalay offers quantitative definition for additive (CI $=1$ ), synergism $(\mathrm{CI}<1)$, and antagonism $(\mathrm{CI}>1)$ effects in drug combinations. The data were also graphically expressed as isobolograms.

2.8. Scanning Electron Microscopy (SEM). To evaluate the effect of the A3K2A3 on the morphology of the parasite by SEM, parasitic forms and LLCMK 2 cells were treated at the concentrations that corresponded to the $\mathrm{IC}_{50}$ and $\mathrm{IC}_{90}$ (epimastigotes and amastigotes for $72 \mathrm{~h}$ ) or $\mathrm{EC}_{50}$ and $\mathrm{EC}_{90}$ (trypomastigotes for $24 \mathrm{~h}$ ). The parasites were collected, washed, and fixed in $2.5 \%$ glutaraldehyde in $0.1 \mathrm{M}$ sodium cacodylate buffer at $4^{\circ} \mathrm{C}$ for $24 \mathrm{~h}$. After, they were added onto glass coverslips containing poly-L-lysine, dehydrated in increasing gradient of ethanol, dried by the critical-point method using $\mathrm{CO}_{2}$, coated with gold, and observed in Shimadzu SS-550 SEM.

In the images obtained by SEM, protozoa were analyzed for changes in their cell surface, number and flagella morphology, leakage of cytoplasmic contents, and size and cell shape changes.

2.9. Transmission Electron Microscopy (TEM). To evaluate the effect of the $\mathbf{A} \mathbf{3} \mathbf{K} \mathbf{2} \mathbf{A} \mathbf{3}$ on the ultrastructure of the parasite by TEM, treated parasitic forms were collected and fixed under the same conditions as the SEM. The postfixation was performed in a solution of $1 \% \mathrm{OsO}_{4}, 0.8 \%$ potassium ferricyanide, and $10 \mathrm{mM} \mathrm{CaCl}_{2}$, dehydrated in acetone, and embedded in Polybed 812 resin. Ultrathin sections were obtained, contrasted with uranyl acetate and lead citrate, and observed in JEOL JM 1400 TEM.

2.10. Statistical Analysis. All of the quantitative experiments were performed in at least three independent experiments in duplicate. The statistical analyses were performed using GraphPad Prism ${ }^{\circledR}$ Software (GraphPad Software, California, USA). The data were analyzed using one-way analysis of variance (ANOVA), and the Tukey post hoc test was used to compare means when appropriate. Values of $p \leq 0.05$ were considered statistically significant.

\section{Results}

3.1. A3K2A3 Inhibits the Proliferation of Epimastigote Forms of Trypanosoma cruzi. The compound A3K2A3 showed activity against all three forms of Trypanosoma cruzi. In epimastigotes the compounds caused a dose-dependent inhibition of growth of protozoa, exhibiting an $\mathrm{IC}_{50}$ of $1.99 \pm$ $0.17 \mu \mathrm{M}$ in the treatment for $96 \mathrm{~h}$. By monitoring the number of parasites every $24 \mathrm{~h}$, we noticed that a large proportion of the effect was reached after $24 \mathrm{~h}$ incubation (Figure 2). It is important to note that the activity of the compound was more effective than the standard drug benznidazole $\left(\mathrm{IC}_{50}\right.$ of $6.4 \mu \mathrm{M})[10]$.

3.2. A3K2A3 Decreases the Viability of Trypomastigote Forms of Trypanosoma cruzi. The effect of compound A3K2A3 was evaluated against trypomastigotes in experiments with and without addition of blood and at two different temperatures. The results (Figure 3) showed a marked reduction in the activity of the compounds in the presence and absence of blood and at $4^{\circ} \mathrm{C}\left(\mathrm{EC}_{50}>450.0 \mu \mathrm{M}\right)$ when compared to the effects of the compound at $37^{\circ} \mathrm{C}$. A3K2A3 exhibited a slightly more pronounced effect on trypomastigotes in the presence of blood at $37^{\circ} \mathrm{C}\left(\mathrm{EC}_{50} 11.3 \pm 1.17 \mu \mathrm{M}\right)$ when compared to the same assay, but in the absence of blood $\left(\mathrm{EC}_{50} 15.57 \pm\right.$ $0.34 \mu \mathrm{M})$. 

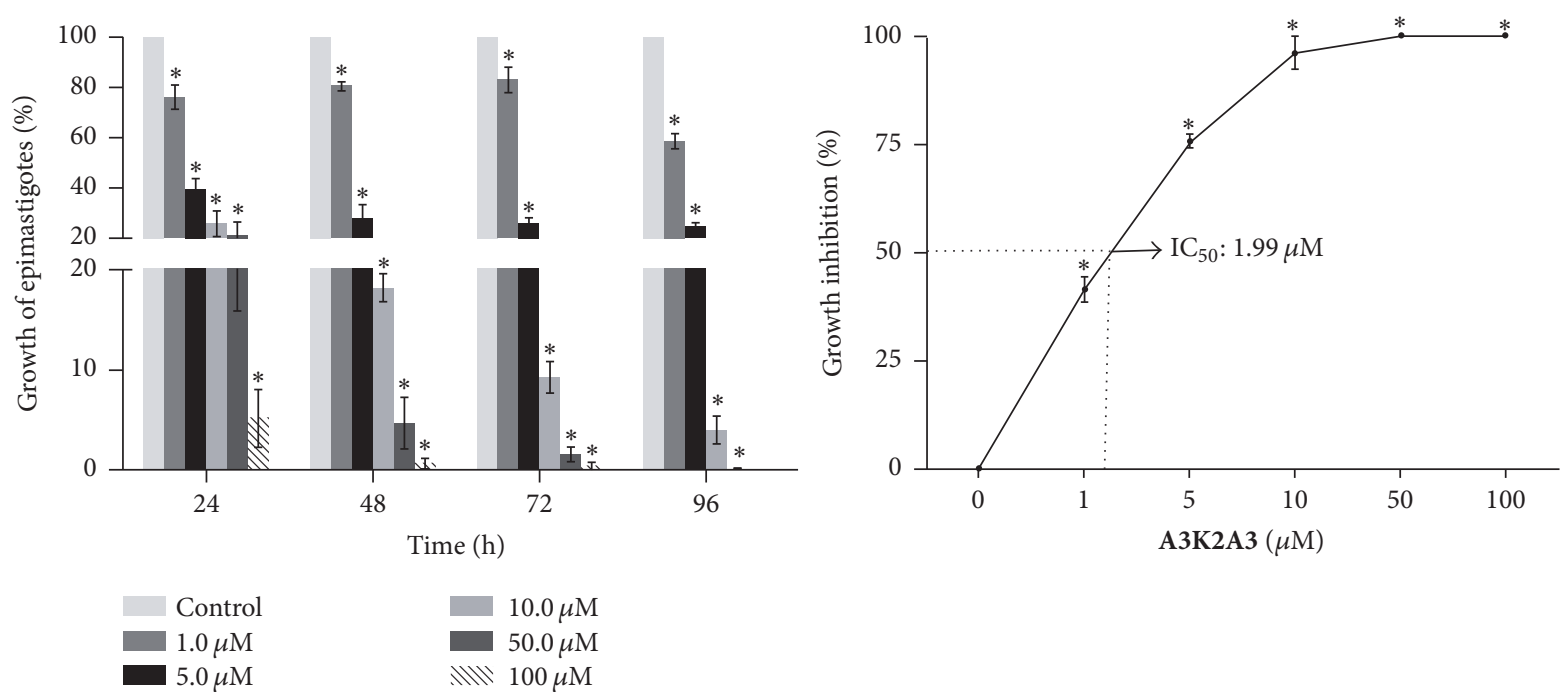

FIgURE 2: Antiproliferative activity of A3K2A3 against the epimastigote forms of T. cruzi. The parasite was incubated in the absence or presence of different concentrations of A3K2A3, and cell growth was analyzed 24, 48, 72, and $96 \mathrm{~h}$ after treatment. The results are expressed as percentages $\pm \mathrm{SD}$ of growth compared to untreated parasites of at least three independent experiments. The dotted line represents the $\mathrm{IC}_{50}$ value after $96 \mathrm{~h}$ of treatment. ${ }^{*} p \leq 0.05$, significant difference relative to the control group (untreated parasites).

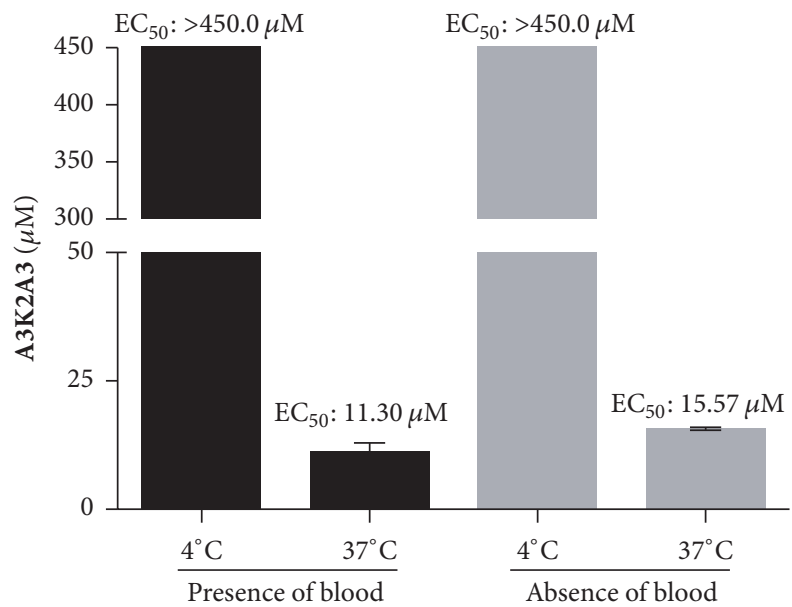

Figure 3: Activity of A3K2A3 against trypomastigote forms of $T$. cruzi. Effective concentration $\left(\mathrm{EC}_{50}\right)$ of $\mathbf{A} 3 \mathbf{K} 2 \mathrm{~A} 3$ that inhibited the viability of $50 \%$ of the trypomastigotes after $24 \mathrm{~h}$ incubation, assays conducted with presence or absence of blood at $4^{\circ} \mathrm{C}$ and $37^{\circ} \mathrm{C}$. Results are expressed as mean $\pm \mathrm{SD}$ of at least three independent experiments.

\subsection{A3K2A3 Induces Trypanocidal Effect on Amastigote} Forms of Trypanosoma cruzi. A3K2A3 also exerted inhibitory effect against intracellular amastigotes. After $96 \mathrm{~h}$ incubation in presence of the compound, the percentages of infected $\mathrm{LLCMK}_{2}$ cells and mean number of intracellular amastigotes per infected cells were reduced in comparison with the untreated control (Figure 4). Both parameters are expressed together as the survival rate. A3K2A3 compound inhibited the growth of $50 \%$ of amastigotes at concentration $1.20 \pm 0.16 \mu \mathrm{M}$. Additionally, A3K2A3 showed no toxicity in mammalian LLCMK ${ }_{2}$ cells with $50.0 \mu \mathrm{M}$, a concentration that completely reduced the proliferation of intracellular amastigotes (Figure 4(f)).

3.4. A3K2A3 Does Not Cause Toxicity in Red Blood Cells. In order to check the toxicity of the compounds the hemolytic potential was assessed. Red blood cells were incubated in the presence of different concentrations of A3K2A3 for $3 \mathrm{~h}$. After incubation, the highest concentration tested $(1000.0 \mu \mathrm{M})$ did not induce hemolysis (Figure 5).

3.5. The Combination of $\mathbf{A} \mathbf{3 K 2 A 3}$ with Benznidazole, Ketoconazole, or Fluconazole Induces Effects on Trypanosoma cruzi and $\mathrm{LLCMK}_{2}$ Cells. In order to improve the activity of A3K2A3 and get synergistic effect combinations between this compound and benznidazole, ketoconazole, or fluconazole were performed. These combinations were tested on epimastigotes, trypomastigotes, and $\mathrm{LLCMK}_{2}$ cells.

The combination of benznidazole and A3K2A3 despite showing antagonistic effect on epimastigotes (CI of 1.66) (Figure 6(a)) and on LLCMK 2 cells (CI of 1.07) (Figure 6(c)) showed synergistic effect on trypomastigotes (CI of 0.77 ) (Figure 6(b)).

The combination of ketoconazole and A3K2A3 showed synergistic effect on epimastigotes (CI of 0.80) (Figure 6(d)) and antagonistic effect on $\mathrm{LLCMK}_{2}$ cells (CI of 1.21) (Figure 6(f)) and on trypomastigotes (CI of 1.39) (Figure 6(e)).

The combination of fluconazole and A3K2A3 also showed antagonistic effect on epimastigotes (CI of 1.26) and trypomastigotes (CI of 1.35) (Figures 6(g) and 6(h)), but on $\mathrm{LLCMK}_{2}$ cells the effect is synergistic (CI of 0.65) (Figure 6(i)). 


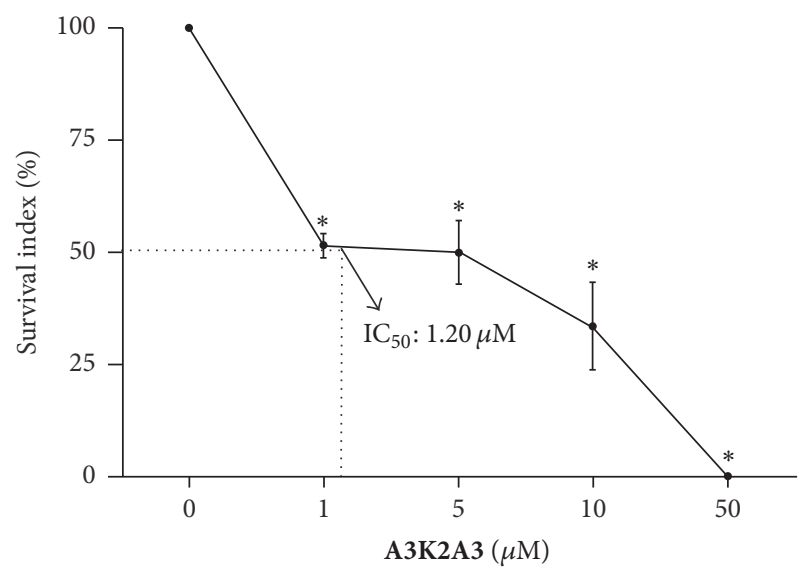

(a)

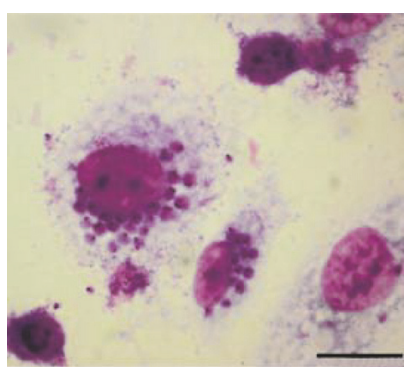

(c)

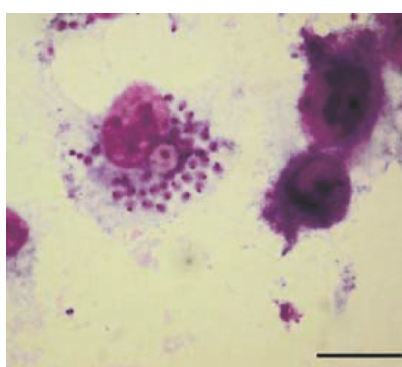

(d)

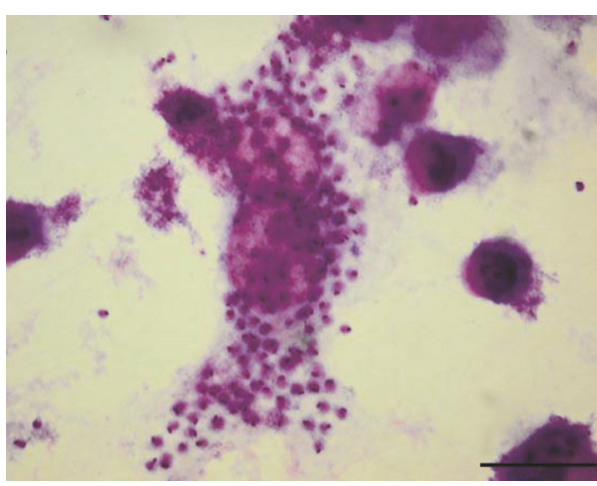

(b)

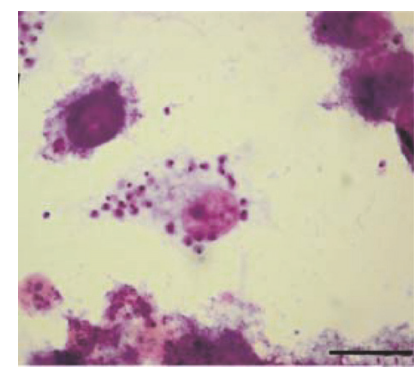

(e)

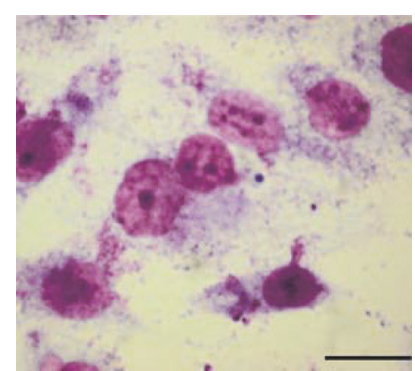

(f)

FIgURE 4: Antiproliferative activity of A3K2A3 against intracellular amastigote forms of T. cruzi after $96 \mathrm{~h}$ of treatment. (a) LLCMK cells $^{2}$ were infected with trypomastigotes and then treated with A3K2A3. The data are expressed as the mean values of at least three independent experiments. The values obtained for the survival index of the control group (untreated cells) were normalized to 100\%. The dotted line represents the $\mathrm{IC}_{50}$ value after $96 \mathrm{~h}$ of treatment. ${ }^{*} p \leq 0.05$, significant difference of each group from control. Light microscopy of $T$. cruziinfected LLCMK 2 cells treated for $96 \mathrm{~h}$. (b) Controls cells. (c, d, e, f) Cells treated with 1.0, 5.0, 10.0, and 50.0 $\mu \mathrm{M}$ of A3K2A3, respectively. Bars $=20.0 \mu \mathrm{m}$.

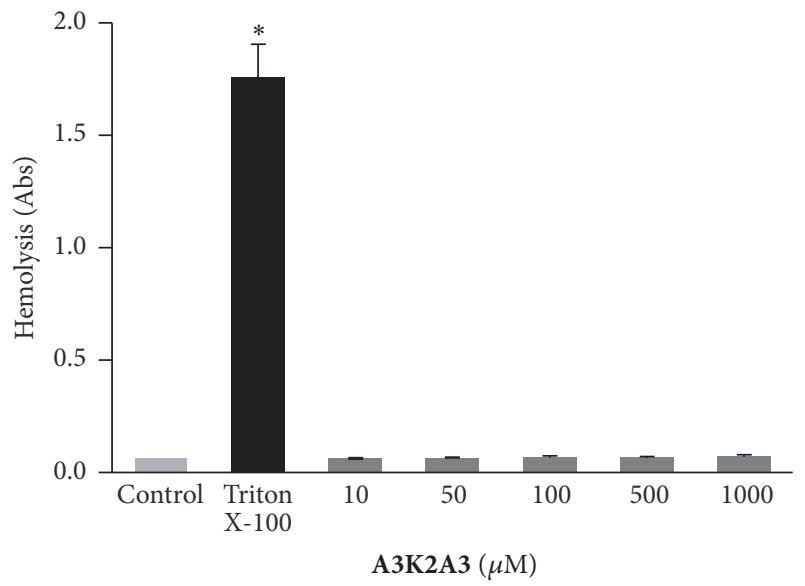

Figure 5: Hemolytic properties of A3K2A3 on human red blood cells. Triton X-100 was used as a positive control. Results are expressed as mean $\pm \mathrm{SD}$ of at least three independent experiments. ${ }^{*} p \leq 0.05$, significant difference of each group from control.

3.6. A3K2A3 Induces Alterations in Trypanosoma cruzi Morphology and Ultrastructure. Ultrastructural and morphological alterations induced by treatment with A3K2A3 were evaluated by transmission electron microscopy and scanning electron microscopy, respectively. The parasites treated with A3K2A3 presented serious structural changes in the three evolutionary forms (Figure 7). The morphological changes were more evidenced in epimastigotes and trypomastigotes (Figures 7(B) and 7(D)). Untreated cells showed normal organelles (Figures 7(a), 7(c), and 7(e)). Major ultrastructural changes were quantified, and it was observed that the compound promoted the same changes in three evolutionary forms of T. cruzi (Table 1). The nucleus, the autophagosomelike structures, the mitochondrion, the cytoplasmatic membrane, and the Golgi complex were the structures most affected. We also observed the formation of myelin-like figures and a large increase in the number of autophagosomelike structures and lipid-storage bodies (Figures $7(\mathrm{~b}), 7(\mathrm{~d})$, and $7(\mathrm{f}))$. The morphology of the parasites treated with the compound showed alterations mainly on epimastigote and trypomastigote forms. The main morphological alterations induced by treatment with this compound were rounding and reduction of the cellular body and loss of flagellum in both parasitic forms (Figures 7(B) and 7(D)). Amastigote forms showed no significant morphological changes (Figure $7(\mathrm{~F})$ ). However, a reduction in the number of intracellular amastigotes was observed (Figure $7(\mathrm{~F})$ ). 


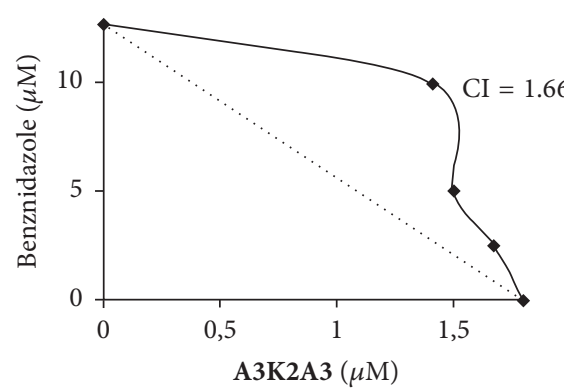

(a)

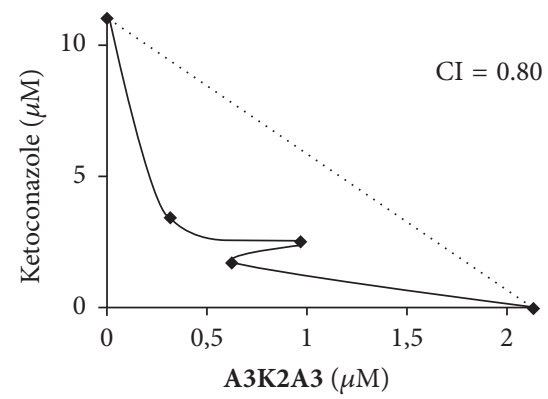

(d)

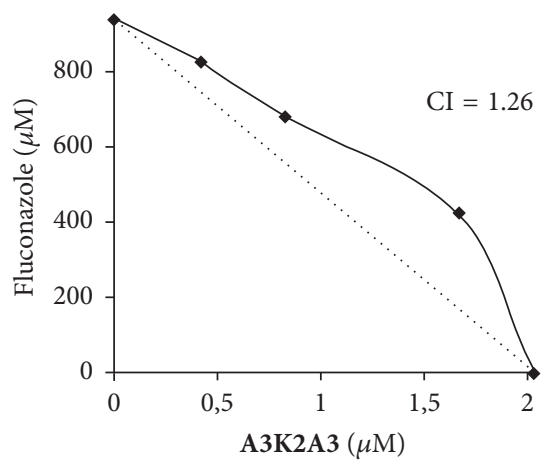

(g)

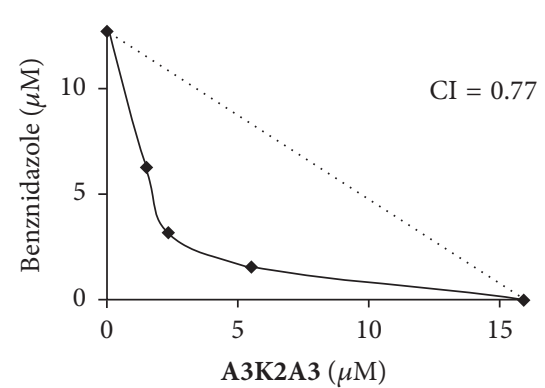

(b)

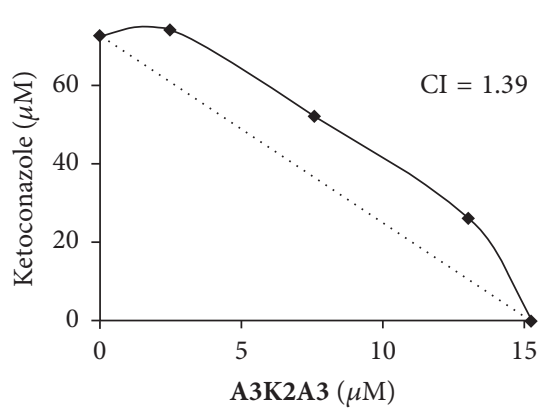

(e)

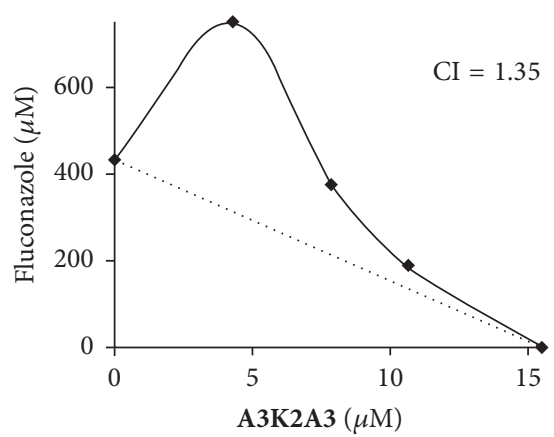

(h)

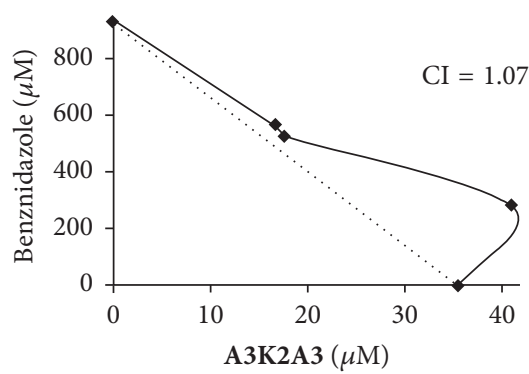

(c)

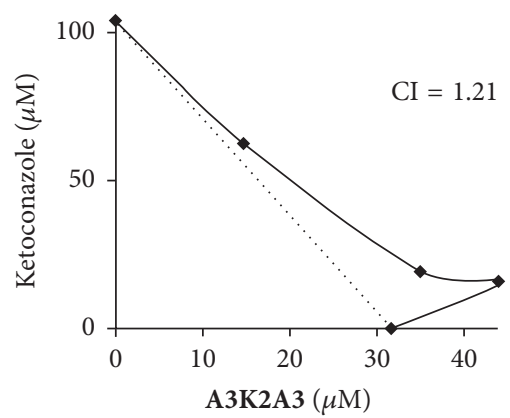

(f)

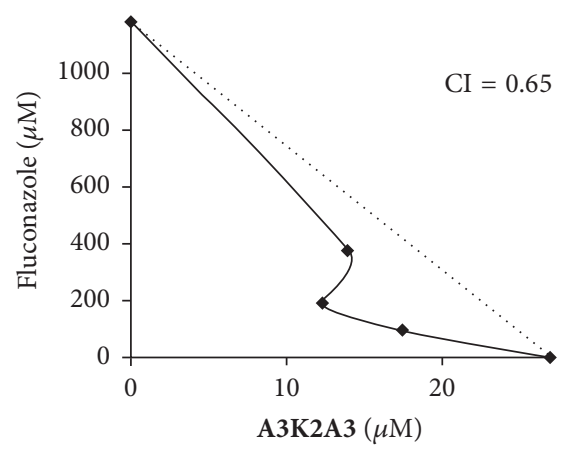

(i)

FIGURE 6: Isobolograms of drugs combinations. Effect of the combination of A3K2A3 and benznidazole against epimastigotes (a), trypomastigotes (b), and LLCMK 2 cells (c). Effect of the combination of A3K2A3 and ketoconazole against epimastigotes (d), trypomastigotes (e), and LLCMK 2 cells (f). Effect of the combination of A3K2A3 and fluconazole against epimastigotes (g), trypomastigotes (h), and LLCMK 2 cells (i). The dotted lines correspond to the additivity effect. Points below the line indicate a synergistic effect. Points above the line indicate an antagonistic effect. The experiment was repeated three times. The points show median values.

\section{Discussion}

Dibenzylideneacetones are compounds characterized by a broad spectrum of biological activity and exhibit important biological activities against several infections [22-24]. The dibenzylideneacetone A3K2A3 evaluated in this study has two nitro groups attached directly to an aromatic ring system $[26,32]$.

A3K2A3 exhibited strong anti-Trypanosoma cruzi activity against the main forms of the parasite. This compound showed better activity against the parasites than did the reference drug, benznidazole $\left(\mathrm{IC}_{50 \text { epi }}: 6.5 \mu \mathrm{M} ; \mathrm{EC}_{50 \text { trypo }}\right.$ : $\left.34.5 \mu \mathrm{M} ; \mathrm{IC}_{50 \mathrm{ama}}: 19.2 \mu \mathrm{M}\right)$ [10]. These results are especially interesting because it demonstrates that this compound can be promising chemotherapeutic agent against T. cruzi.

The presence of two nitro groups in A3K2A3 can justify its good activity against this protozoan, since the nitro group is essential for the action of the drug. These results are consistent with the literature, which showed that nitroreductase enzymes, found in trypanosomes and absent in mammals [33-36], may activate $\mathrm{NO}_{2}$-containing drugs into a more active form [26]. Nitroreductase enzymes have two categories, the type I NTRs (oxygen-insensitive) which perform reduction of two electrons and do not result in the production of reactive oxygen species (ROS), and type II NTRs (sensitive to oxygen) which perform reduction of an electron leading 
TABle 1: Summary of damage on Trypanosoma cruzi observed by transmission electron microscopy, after $24 \mathrm{~h}$ exposure to compound A3K2A3.

\begin{tabular}{|c|c|c|c|c|c|c|}
\hline \multirow{3}{*}{ Structure } & \multicolumn{6}{|c|}{ Damage $(\%)^{\mathrm{a}, \mathrm{b}}$} \\
\hline & \multicolumn{2}{|c|}{ Epimastigotes } & \multicolumn{2}{|c|}{ Trypomastigotes } & \multicolumn{2}{|c|}{ Amastigotes } \\
\hline & Untreated & $\mathrm{IC}_{50}$ & Untreated & $\mathrm{EC}_{50}$ & Untreated & $\mathrm{IC}_{50}$ \\
\hline Mitochondrion & 08 & 68 & 02 & 75 & 06 & 65 \\
\hline Plasmatic membrane & 08 & 76 & 01 & 50 & 02 & 28 \\
\hline Cell division & 04 & 36 & - & - & 06 & 19 \\
\hline Nucleus & 12 & 84 & 08 & 65 & 02 & 19 \\
\hline Autophagic vacuoles & 04 & 62 & 09 & 80 & 06 & 14 \\
\hline Lipid vacuoles & 04 & 20 & 11 & 40 & 00 & 02 \\
\hline Golgi complex & 00 & 48 & 00 & 70 & 01 & 05 \\
\hline Myelin figures & 00 & 04 & 00 & 05 & 00 & 01 \\
\hline
\end{tabular}

${ }^{\mathrm{a}}$ For each compound, 100 parasites were analyzed.

${ }^{\mathrm{b}}$ Damage frequency: $0 \%=$ no damage; $100 \%=$ maximum damage.

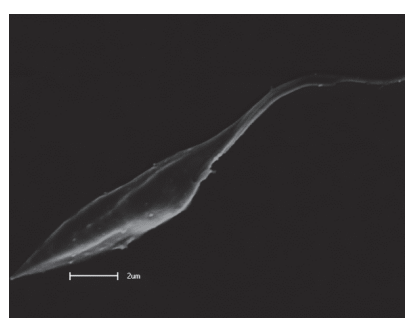

(A)

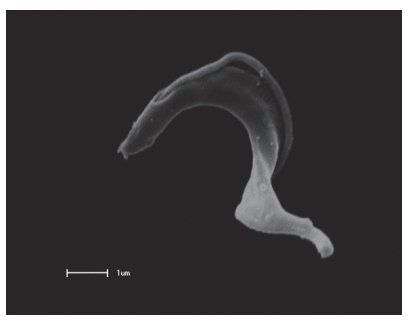

(C)

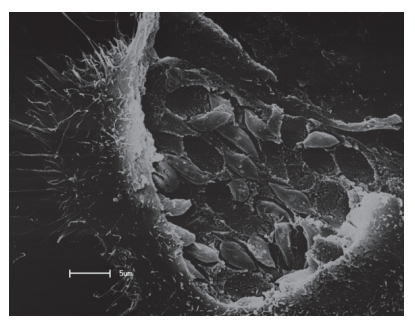

(E)

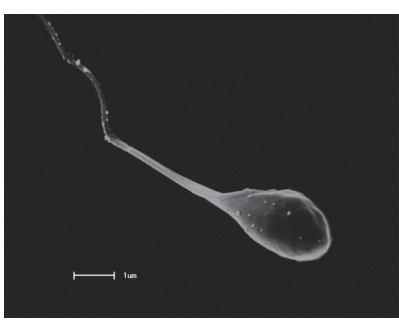

(B)

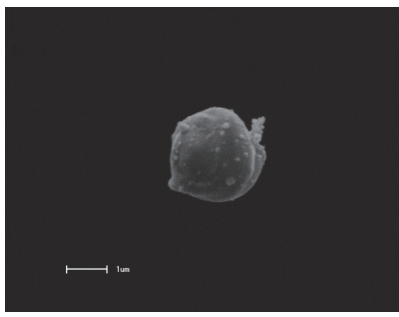

(D)

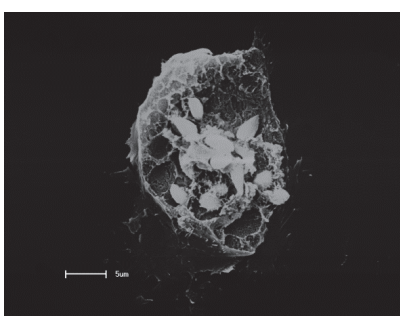

(F)

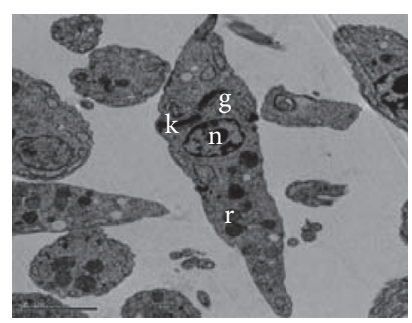

(a)

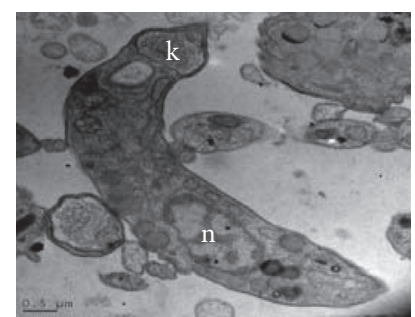

(c)

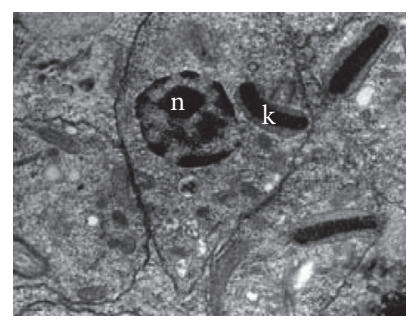

(e)

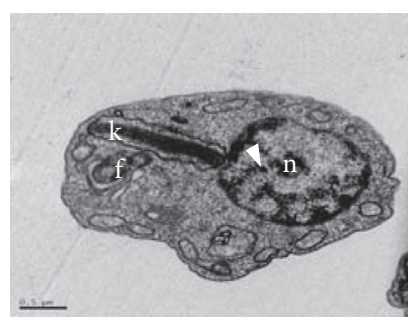

(b)

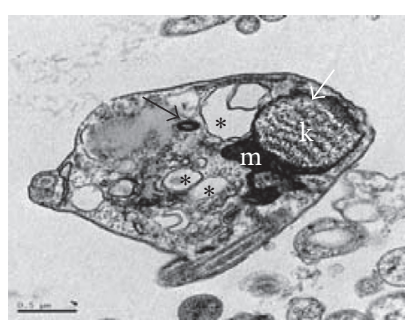

(d)

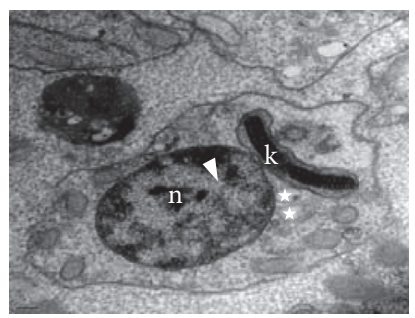

(f)

FIgURE 7: Scanning electron microscopy and transmission electron microscopy of epimastigote forms of Trypanosoma cruzi treated with A3K2A3 for $72 \mathrm{~h}$ at $28^{\circ} \mathrm{C}$ and trypomastigotes and amastigotes forms of Trypanosoma cruzi treated with A3K2A3 for $24 \mathrm{~h}$ at $37^{\circ} \mathrm{C}$. Uppercase letters correspond to scanning electron microscopy and lowercase letters correspond to electronic transmission microscopy. (A, a) Untreated epimastigotes, $(\mathrm{C}, \mathrm{c})$ untreated trypomastigotes, and (E, e) untreated amastigotes exhibited normal morphology and organelles. (B, b) Epimastigotes treated with $\mathrm{IC}_{50}$ of $\mathbf{A} 3 \mathbf{K} 2 \mathrm{~A} 3$ exhibited reduction and rounding of the cell volume and nuclear disorganization (white arrow head). (D, d) Trypomastigotes treated with $\mathrm{EC}_{50}$ of A3K2A3 exhibited reduction and rounding of the cell volume and concentric myelin-like membrane structures (black arrow), autophagosome-like structures (asterisk), and mitochondrial swelling (white arrow). (F, f) Amastigotes treated with $\mathrm{IC}_{50}$ of $\mathbf{A} 3 \mathbf{K} \mathbf{2} \mathbf{A} 3$ exhibited normal morphology and lipid-storage bodies (star) and nuclear disorganization (white arrow head). Bars $=5 \mu \mathrm{m}(\mathrm{E}, \mathrm{F}) ;$ bars $=2 \mu \mathrm{m}(\mathrm{A}, \mathrm{a})$; bars $=1 \mu \mathrm{m}(\mathrm{B}, \mathrm{C}, \mathrm{D})$; bars $=0.5 \mu \mathrm{m}(\mathrm{b}, \mathrm{c}, \mathrm{d})$; bars $=0.2 \mu \mathrm{m}(\mathrm{e}, \mathrm{f})$. $\mathrm{n}$, nucleus; $\mathrm{r}$, reservosomes; $\mathrm{m}$, mitochondrion; k, kinetoplast; g, Golgi complex; f, flagellum. 
to the production of an unstable nitro-radical that in the presence of oxygen results in the production of superoxide anions [37-40].

When the compound was tested on trypomastigotes at $4^{\circ} \mathrm{C}$, a drastic reduction of activity of the $\mathbf{A} 3 \mathbf{K} 2 \mathrm{~A} 3 \mathrm{com}-$ pound was observed. This reduction mediated by the low temperature was also analyzed in other compounds [41] and should be related to the compromised enzymes activity of the parasite. The literature shows that low temperatures affect the enzymatic activity because, from a certain temperature, reaction rate decreases sharply [42]. A3K2A3 is nitro compound, presenting in its chemical structure the presence of nitro groups attached directly to an aromatic ring [26]. The literature reports that the bioactivity of nitro compounds is related to its reduction, acting as a prodrug [32]. In fact, a metabolomic study of A3K2A3 performed by Din et al. (2016) disclosed that the action of T. cruzi can modify the A3K2A3 compound in the result of metabolism. This investigation confirmed that enzymes of T. cruzi play a pivotal role in drug activation [43], which may explain the drastic reduction of activity of the A3K2A3 compound in trypomastigotes at $4^{\circ} \mathrm{C}$.

An important criterion in the search for compounds active against T. cruzi with therapeutic potential is that they are not toxic to the mammalian host cells. According to Garratty [44] some drugs can induce immune hemolytic anemia (DIIHA) so it is important to check the hemolytic capacity of the compounds. A3K2A3 showed no hemolytic activity and high selectivity index for the three evolutionary forms, epimastigotes $\left(\mathrm{SI}_{\mathrm{A} 3 \mathrm{~K} 2 \mathrm{~A} 3}: 15.77\right)$, trypomastigotes $\left(\mathrm{SI}_{\mathrm{A} 3 \mathrm{~K} 2 \mathrm{~A} 3}\right.$ : 2.01), and amastigotes $\left(\mathrm{SI}_{\mathrm{A} 3 \mathrm{~K} 2 \mathrm{~A} 3}: 27.16\right)$. The cytotoxicity of this compound also had been evaluated against macrophages J774A1 and LLCMK $_{2}$ cells and results showed that the compound was more toxic to Leishmania amazonensis and T. cruzi than for mammalian cells [26]. Aher et al. [22] also revealed no toxicity of dibenzylideneacetones.

Combination of drugs is an important way to improve the therapeutic efficacy. Generally, the combinations are employed in order to enable a synergetic effect, reducing toxicity, the treatment time, and development of resistance $[45,46]$. Combination of drugs is a promising strategy for the development of new treatments for Chagas disease [47]. In this context, we sought to evaluate the combination of A3K2A3 with the standard drug benznidazole and the azoles, ketoconazole and fluconazole. Azole compounds have been shown to be effective in blocking the proliferation of protozoa parasites such as L. tropica, L. mexicana, and T. cruzi, both in vitro and in vivo $[48,49]$.

The synergistic activity of ketoconazole and benznidazole interaction with other compounds in T. cruzi has already been demonstrated [9, 20, 47, 48, 50, 51]. Fluconazole has shown synergistic effect against other protozoa, when combined with other drugs [52]. A3K2A3 was effective in combination with benznidazole against trypomastigotes and in combination with ketoconazole against epimastigotes. These combinations also exhibited antagonistic effect on $\mathrm{LLCMK}_{2}$ cells. The combination of the compound with fluconazole was not satisfactory. Fluconazole despite having been shown to be active in vitro against T. cruzi [6] cannot stop the progression of the disease $[40,53]$.

Recent research shows that some synthetic compounds promote cellular disorganization in L. infantum affecting mainly the nucleus, mitochondria, and kinetoplast, with frequent disruption of the nuclear membrane, loss of cellular integrity, and accumulation of bodies lipids [54]. In $T$. cruzi, ultrastructural changes as the formation of myelin figures, autophagosomes-like vacuoles, disruption of the Golgi complex, and mitochondria enlargement were observed in response to treatment with inhibitors of sterol biosynthesis $[55,56]$.

In this study, the analysis performed by SEM showed that treatment with $\mathbf{A} 3 \mathbf{K} \mathbf{2} \mathbf{A} 3$ in epimastigotes and trypomastigotes led to morphological changes that affect the flagellum, reduction of the volume, and rounding of the cell. In amastigotes there was no change in morphology. TEM showed that the compound structurally affects mainly the nucleus, mitochondrion, plasma membrane, and Golgi complex in the three parasitic forms. The increased number of autophagosome-like structures also was observed. The presence of these structures could imply the existence of process of autophagy.

Intense cytoplasmic vacuolization and structural disorganization of the parasite cell, together with mitochondrial swelling, were also observed after treatment with other compounds in T. cruzi $[10,57,58]$. Mitochondrion of T. cruzi presents unique functional and structural features, which are remarkably different from mammalian mitochondria. These features make this organelle an exceptionally attractive chemotherapeutic target [41].

Altogether, our findings support the possibility that different mechanisms may be related to the action of the A3K2A3 against T. cruzi. Despite the fact that many of the specific targets of drugs used against T. cruzi are known, it is reasonable to suppose that one compound could act on more than one target with independent or combined action, as well as in a single preferred pathway.

\section{Conclusions}

In conclusion, the present study demonstrated the strong trypanocidal activity of $\mathbf{A} 3 \mathbf{K} \mathbf{2} \mathbf{A} 3$ on the three forms of T. cruzi. These effects were marked by morphological and ultrastructural changes in this parasite. The data suggest that A3K2A3 might be promising compound for the treatment of Chagas disease because its action is active in more than one target on $T$. cruzi. In addition, the combination of A3K2A3 with benznidazole was the most promising, because it increased the effectiveness against trypomastigotes, the clinically relevant form of T. cruzi. Therefore, our results support additional in vivo studies using this drug combination in infected animals.

\section{Conflicts of Interest}

The authors declare that there are no conflicts of interest. 


\section{Acknowledgments}

This study was supported by grants from the Conselho Nacional de Desenvolvimento Científico e Tecnológico (CNPq), Capacitação de Aperfeiçoamento de Pessoal de Nível Superior (CAPES), Financiadora de Estudos e Projetos (FINEP), Programa de Núcleos de Excelência (PRONEX/ Fundação Araucária), Programa de Pós-Graduação em Ciências Biológicas da Universidade Estadual de Maringá, and Central de Microscopia do Complexo de Centrais de Apoio a Pesquisa (COMCAP-UEM).

\section{References}

[1] WHO., Chagas disease (American trypanosomiasis), 2014, http:// www.who.int/mediacentre/factsheets/fs340/en/.

[2] N. A. Andreolo and O. Malafaia, "Os 100 anos da doença de Chagas no Brasil," Arquivos Brasileiros de Cirurgia Digestiva, vol. 22, pp. 189-191, 2009.

[3] C. Chagas, "Nova tripanozomiaze humana: estudos sobre a morfolojia e o ciclo evolutivo do Schizotrypanum cruzi n. gen., n. sp., ajente etiolojico de nova entidade morbida do homem," Memórias do Instituto Oswaldo Cruz, vol. 22, pp. 189-191, 1909.

[4] A. Rassi Jr., A. Rassi, and J. A. Marin-Neto, "Chagas disease," Lancet, vol. 375, pp. 1388-1402, 2010.

[5] A. H. Kollien and G. A. Schaub, "The development of Trypanosoma cruzi in triatominae," Parasitology Today, vol. 16, no. 9, pp. 381-387, 2000.

[6] J. R. Coura, "Present situation and new strategies for Chagas disease chemotherapy-A proposal," Memórias do Instituto Oswaldo Cru, vol. 104, pp. 549-554, 2009.

[7] L. T. D. Tonin, M. R. Panice, C. V. Nakamura et al., "Antitrypanosomal and antileishmanial activities of novel N-alkyl-(1phenylsubstituted- $\beta$-carboline)-3-carboxamides," Biomedicine \& Pharmacotherapy, vol. 64, pp. 386-389, 2010.

[8] E. N. da Silva Júnior, M. C. B. de Souza, M. C. Fernandes et al., "Synthesis and anti-Trypanosoma cruzi activity of derivatives from nor-lapachones and lapachones," Bioorganic \& Medicinal Chemistry, vol. 16, pp. 5030-5038, 2008.

[9] J. H. D. S. Rodrigues, T. Ueda-Nakamura, A. G. Corrêa, D. P. Sangi, and C. V. Nakamura, "A quinoxaline derivative as a potent chemotherapeutic agent, alone or in combination with benznidazole, against Trypanosoma cruzi," PLoS ONE, vol. 9, no. 1, Article ID e85706, 2014.

[10] E. Izumi, T. Ueda-Nakamura, V. F. Veiga, A. C. Pinto, and C. V. Nakamura, "Terpenes from copaifera demonstrated in vitro antiparasitic and synergic activity," Journal of Medicinal Chemistry, vol. 55, no. 7, pp. 2994-3001, 2012.

[11] E. Izumi, T. Ueda-Nakamura, B. P. Dias Filho, V. F. Veiga Júnior, and C. V. Nakamura, "Natural products and Chagas disease: a review of plant compounds studied for activity against Trypanosoma cruzi," Natural Product Reports, vol. 28, pp. 809823, 2011.

[12] R. H. Valdez, L. T. D. Tonin, T. Ueda-Nakamura et al., "Biological activity of 1,2,3,4-tetrahydro- $\beta$-carboline-3-carboxamides against Trypanosoma cruzi," Acta Tropica, vol. 110, no. 1, pp. 7$14,2009$.

[13] M. P. Barrett and S. L. Croft, "Management of trypanosomiasis and leishmaniasis," British Medical Bulletin, vol. 104, no. 1, pp. 175-196, 2012.
[14] A. A. Messadi, T. Lamia, B. Kamel, O. Salima, M. Monia, and B. R. Saida, "Association between antibiotic use and changes in susceptibility patterns of Pseudomonas aeruginosa in an intensive care burn unit: a 5-year study, 2000-2004," Burns, vol. 34, no. 8, pp. 1098-1102, 2008.

[15] M. M. Sopirala, J. E. Mangino, W. A. Gebreyes et al., "Synergy testing by etest, microdilution checkerboard, and timekill methods for pan-drug-resistant Acinetobacter baumannii," Antimicrobial Agents and Chemotherapy, vol. 54, no. 11, pp. 4678-4683, 2010.

[16] E. Kamysz, O. Simonetti, O. Cirioni et al., "In vitro activity of the lipopeptide PAL-Lys-Lys-NH2, alone and in combination with antifungal agents, against clinical isolates of Candida spp.," Peptides, vol. 32, no. 1, pp. 99-103, 2011.

[17] E. H. Endo, D. A. Garcia Cortez, T. Ueda-Nakamura, C. V. Nakamura, and B. P. Dias Filho, "Potent antifungal activity of extracts and pure compound isolated from pomegranate peels and synergism with fluconazole against Candida albicans," Research in Microbiology, vol. 161, pp. 534-540, 2010.

[18] J. El-On, E. Bazarsky, and R. Sneir, "Leishmania major: in vitro and in vivo anti-leishmanial activity of paromomycin ointment (Leshcutan) combined with the immunomodulator Imiquimod," Experimental Parasitology, vol. 116, no. 2, pp. 156162,2007

[19] N. Mbongo, P. M. Loiseau, D. G. Craciunescu, and M. RobertGero, "Synergistic effect of Ir-(COT)-pentamidine alizarin red and pentamidine, amphotericin B, and paromomycin on Leishmania donovani," Acta Tropica, vol. 70, no. 2, pp. 239-245, 1998.

[20] R. H. Valdez, L. T. D. Tonin, T. Ueda-Nakamura et al., "In Vitro and in Vivo trypanocidal synergistic activity of N-butyl-1- (4dimethylamino)phenyl-1,2,3,4-tetrahydro- $\beta$-carboline-3- carboxamide associated with benznidazole," Antimicrobial Agents and Chemotherapy, vol. 56, no. 1, pp. 507-512, 2012.

[21] K. J. Pelizzaro-Rocha, T. S. Tiuman, E. Izumi, T. UedaNakamura, B. P. D. Filho, and C. V. Nakamura, "Synergistic effects of parthenolide and benznidazole on Trypanosoma cruzi," Phytomedicine, vol. 18, no. 1, pp. 36-39, 2010.

[22] R. B. Aher, G. Wanare, N. Kawathekar et al., "Dibenzylideneacetone analogues as novel Plasmodium falciparum inhibitors," Bioorganic \& Medicinal Chemistry Letters, vol. 21, pp. 30343036, 2011

[23] H.-E. Lee, E.-S. Choi, J.-Y. Jung, M.-J. You, L.-H. Kim, and S.-D. Cho, "Inhibition of specificity protein 1 by dibenzylideneacetone, a curcumin analogue, induces apoptosis in mucoepidermoid carcinomas and tumor xenografts through Bim and truncated Bid," Oral Oncology, vol. 50, no. 3, pp. 189-195, 2014.

[24] H.-J. Yu, J.-A. Shin, J.-S. Nam, B. S. Kang, and S.-D. Cho, "Apoptotic effect of dibenzylideneacetone on oral cancer cells via modulation of specificity protein 1 and Bax," Oral Diseases, vol. 19, no. 8, pp. 767-774, 2013.

[25] S. Prasad, V. R. Yadav, J. Ravindran, and B. B. Aggarwal, "ROS and $\mathrm{CHOP}$ are critical for dibenzylideneacetone to sensitize tumor cells to TRAIL through induction of death receptors and downregulation of cell survival proteins," Cancer Research, vol. 71, no. 2, pp. 538-549, 2011.

[26] Z. Ud Din, T. P. Fill, F. F. de Assis et al., "Unsymmetrical 1,5diaryl-3-oxo-1,4-pentadienyls and their evaluation as antiparasitic agents," Bioorganic \& Medicinal Chemistry, vol. 22, pp. 11211127, 2014.

[27] E. P. Camargo, "Growth and differentiation in Trypanosoma cruzi. I. Origin of metacyclic trypanosomes in liquid media," 
Revista do Instituto de Medicina Tropical de São Paulo, vol. 6, pp. 93-100, 1964.

[28] Z. Brener, "Therapeutic activity and criterion of cure on mice experimentally infected with Trypanosoma cruzi," Revista do Instituto de Medicina Tropical de São Paulo, vol. 4, pp. 389-396, 1962.

[29] T. Chou and P. Talalay, "Quantitative analysis of dose-effect relationships: the combined effects of multiple drugs or enzyme inhibitors," Advances in Enzyme Regulation, vol. 22, pp. 27-55, 1984.

[30] L. Zhao, J. L. Au, and M. G. Wientjes, "Comparison of methods for evaluating drug-drug interaction," Frontiers in Bioscience, vol. 2, pp. 241-249, 2010.

[31] T. Mosmann, "Rapid colorimetric assay for cellular growth and survival: application to proliferation and cytotoxicity assays," Journal of Immunological Methods, vol. 65, no. 1-2, pp. 55-63, 1983.

[32] S. Patterson and S. Wyllie, "Nitro drugs for the treatment of trypanosomatid diseases: past, present, and future prospects," Trends in Parasitology, vol. 30, no. 6, pp. 289-298, 2014.

[33] J. E. J. Nixon, A. Wang, J. Field et al., "Evidence for lateral transfer of genes encoding ferredoxins, nitroreductases, $\mathrm{NADH}$ oxidase, and alcohol dehydrogenase 3 from anaerobic prokaryotes to Giardia lamblia and Entamoeba histolytica," Eukaryotic Cell, vol. 1, no. 2, pp. 181-190, 2002.

[34] J. Müller, J. Wastling, S. Sanderson, N. Müller, and A. Hemphill, "A novel Giardia lamblia nitroreductase, G1NR1, interacts with nitazoxanide and other thiazolides," Antimicrobial Agents \& Chemotherapy, vol. 51, pp. 1979-1986, 2007.

[35] S. R. Wilkinson, M. C. Taylor, D. Horn, J. M. Kelly, and I. Cheeseman, "A mechanism for cross-resistance to nifurtimox and benznidazole in trypanosomes," Proceedings of the National Academy of Sciences of the United States of America, vol. 105, no. 13, pp. 5022-5027, 2008.

[36] D. Pal, S. Banerjee, J. Cui, A. Schwartz, S. K. Ghosh, and J. Samuelson, "Giardia, Entamoeba, and Trichomonas enzymes activate metronidazole (nitroreductases) and inactivate metronidazole (nitroimidazole reductases)," Antimicrobial Agents \& Chemotherapy, vol. 53, pp. 458-464, 2009.

[37] I. M. de Oliveira, D. Bonatto, J. Antonio, and P. Henriques, "Nitroreductases: enzymes with environmental, biotechnological and clinical importanc," Current Research, Technology and Education Topics in Applied Microbiology and Microbial Biotechnology, vol. 2, pp. 1008-1019, 2010.

[38] F. J. Peterson, R. P. Mason, J. Hovsepian, and J. L. Holtzman, "Oxygen-sensitive and -insensitive nitroreduction by Escherichia coli and rat hepatic microsomes," Journal of Biological Chemistry, vol. 254, pp. 4009-4015, 1979.

[39] R. P. Mason and J. L. Holtzman, "The mechanism of microsomal and mitochondrial nitroreductase. Electron spin resonance evidence for nitroaromatic free radical intermediates," Biochemistry, vol. 14, no. 8, pp. 1626-1632, 1975.

[40] J. A. Urbina and R. Docampo, "Specific chemotherapy of Chagas disease: controversies and advances," Trends in Parasitology, vol. 19, no. 11, pp. 495-501, 2003.

[41] R. F. S. Menna-Barreto, R. L. S. Goncalves, E. M. Costa et al., "The effects on Trypanosoma cruzi of novel synthetic naphthoquinones are mediated by mitochondrial dysfunction," Free Radical Biology and Medicine, vol. 47, no. 5, pp. 644-653, 2009.
[42] D. L. Nelson and M. M. Cox, Princípios de Bioquímica de Lehninger, 5th edition, 2011.

[43] Z. U. Din, D. Lazarin-Bidóia, V. Kaplum, F. P. Garcia, C. V. Nakamura, and E. Rodrigues-Filho, "The structure design of biotransformed unsymmetrical nitro-contained 1,5-diaryl-3oxo-1,4-pentadienyls for the anti-parasitic activities," Arabian Journal of Chemistry, 2016.

[44] G. Garratty, "Drug-induced immune hemolytic anemia," Clinical Advances in Hematology \& Oncology, vol. 8, pp. 98-101, 2010.

[45] N. S. Buchan, D. K. Rajpal, Y. Webster et al., "The role of translational bioinformatics in drug discovery," Drug Discovery Today, vol. 16, no. 9-10, pp. 426-434, 2011.

[46] Y. Y. Li, J. An, and S. J. M. Jones, "A computational approach to finding novel targets for existing drugs," PLoS Computational Biology, vol. 7, no. 9, Article ID e1002139, 2011.

[47] J. D. Planer, M. A. Hulverson, J. A. Arif, R. M. Ranade, R. Don, and F. S. Buckner, "Synergy testing of FDA-approved drugs identifies potent drug combinations against Trypanosoma cruzi," PLoS Neglected Tropical Diseases, vol. 8, no. 7, Article ID e2977, 2014.

[48] J. A. Urbina, K. Lazardi, T. Aguirre, M. M. Piras, and R. Piras, "Antiproliferative synergism of the allylamine SF 86-327 and ketoconazole on epimastigotes and amastigotes of Trypanosoma (Schizotrypanum) cruzi," Antimicrobial Agents \& Chemotherapy, vol. 32, pp. 1237-1242, 1988.

[49] C.-K. Chen, S. S. F. Leung, C. Guilbert, M. P. Jacobson, J. H. Mckerrow, and L. M. Podust, "Structural characterization of CYP51 from Trypanosoma cruzi and Trypanosoma brucei bound to the antifungal drugs posaconazole and fluconazole," PLoS Neglected Tropical Diseases, vol. 4, no. 4, 2010.

[50] R. M. Santa-Rita, R. Lira, H. S. Barbosa, J. A. Urbina, and S. L. de Castro, "Anti-proliferative synergy of lysophospholipid analogues and ketoconazole against Trypanosoma cruzi (Kinetoplastida: Trypanosomatidae): cellular and ultrastructural analysis," Journal of Antimicrobial Chemotherapy, vol. 55, no. 5, pp. 780-784, 2005.

[51] R. López-Muñoz, M. Faúndez, S. Klein et al., “Trypanosoma cruzi: in vitro effect of aspirin with nifurtimox and benznidazole," Experimental Parasitology, vol. 124, no. 2, pp. 167-171, 2010.

[52] É. S. Martins-Duarte, W. De Souza, and R. C. Vommaro, "Toxoplasma gondii: the effect of fluconazole combined with sulfadiazine and pyrimethamine against acute toxoplasmosis in murine model," Experimental Parasitology, vol. 133, no. 3, pp. 294-299, 2013.

[53] J. A. Urbina, "Chemotherapy of Chagas disease," Current Pharmaceutical Design, vol. 8, no. 4, pp. 287-295, 2002.

[54] P. Bilbao-Ramos, C. Galiana-Roselló, M. A. Dea-Ayuela et al., "Nuclease activity and ultrastructural effects of new sulfonamides with anti-leishmanial and trypanocidal activities," Parasitology International, vol. 61, no. 4, pp. 604-613, 2012.

[55] M. V. Braga, F. Magaraci, S. O. Lorente, I. Gilbert, and W. De Souza, "Effects of inhibitors of $\Delta 24(25)$-sterol methyl transferase on the ultrastructure of epimastigotes of Trypanosoma cruzi," Microscopy and Microanalysis, vol. 11, no. 6, pp. 506-515, 2005.

[56] R. L. Kessler, M. J. Soares, C. M. Probst, and M. A. Krieger, "Trypanosoma cruzi response to sterol biosynthesis inhibitors: morphophysiological alterations leading to cell death," PLoS ONE, vol. 8, no. 1, Article ID e55497, 2013. 
[57] M. C. O. Campos, K. Salomão, D. B. Castro-Pinto et al., "Croton cajucara crude extract and isolated terpenes: activity on Trypanosoma cruzi," Parasitology Research, vol. 107, no. 5, pp. 1193-1204, 2010.

[58] P. Veiga-Santos, K. J. Pelizzaro-Rocha, A. O. Santos et al., "In vitro anti-trypanosomal activity of elatol isolated from red seaweed Laurencia dendroidea," Parasitology, vol. 137, pp. 16611670, 2010. 

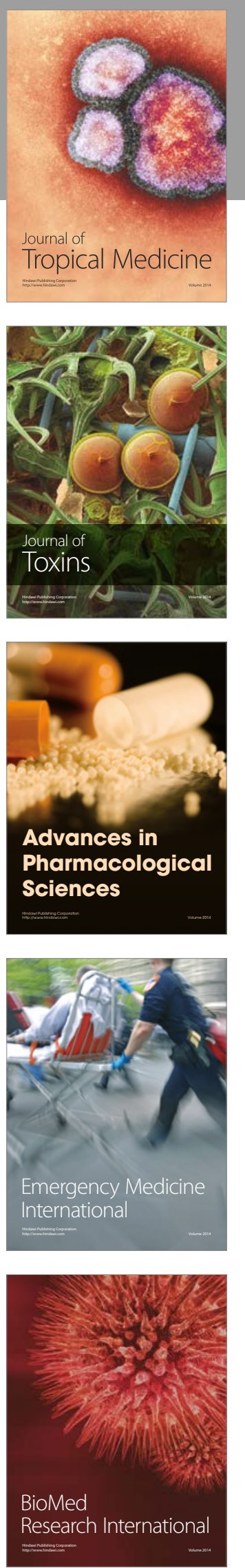
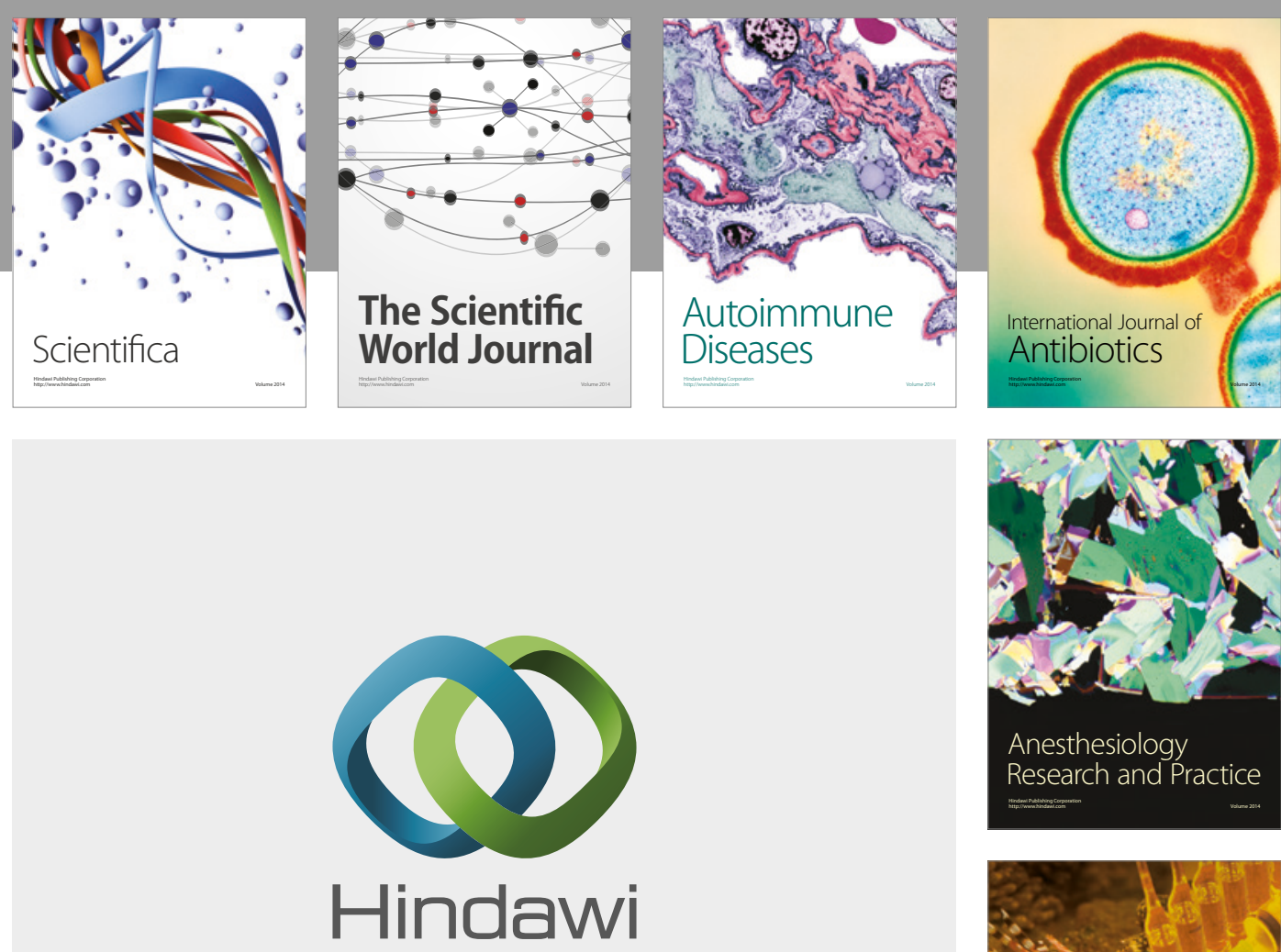

Submit your manuscripts at

https://www.hindawi.com
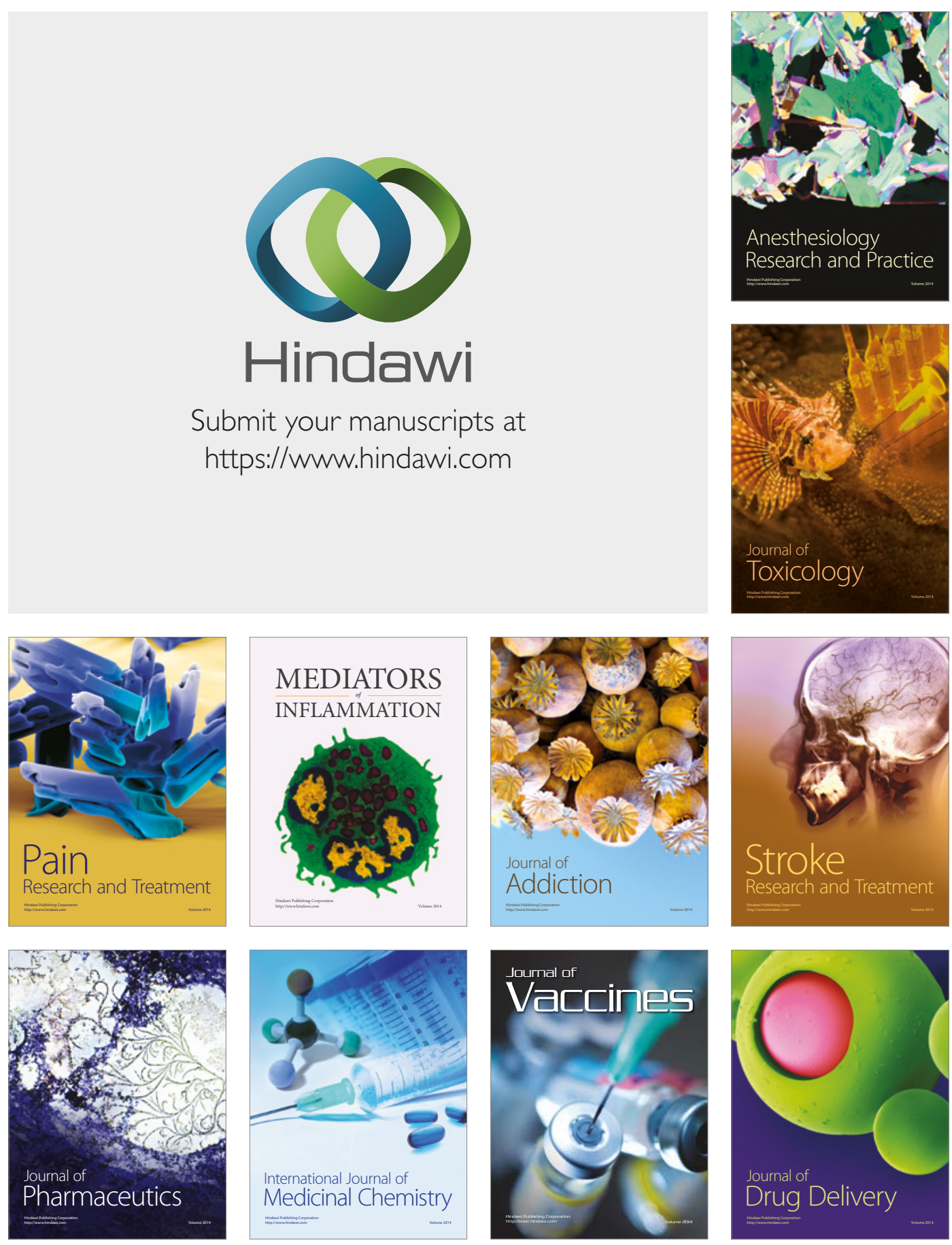